\title{
Research on the Inclusive Finance of Rural Development Based on Internet Finance in China
}

\section{Wang Qing}

School of Economic and Management, Beijing University of Posts and Telecommunication, Beijing, China

\section{Email address:}

wangqingbupt@163.com

\section{To cite this article:}

Wang Qing. Research on the Inclusive Finance of Rural Development Based on Internet Finance in China. Science Innovation. Vol. 4, No. 6, 2016, pp. 267-271. doi: 10.11648/j.si.20160406.14

Received: November 6, 2016; Accepted: November 30, 2016; Published: December 5, 2016

\begin{abstract}
In June 2006, new regulation of Chinese land reform introduced that part of the rural land use rights can be secured loans which would help promote inclusive finance of rural development in China. Since the rise of Internet finance in 2013, and it began to accelerate penetration of rural areas. In virtue of its low cost and convenient operation, Internet finance could promote vigorously the growth of inclusive finance of rural development. The paper analyses the development of inclusive finance of rural development in China and difficulties that have had firstly, then it analyses that how Internet finance affects inclusive finance of rural development from three aspects. In the end of the paper, it puts forward several suggestions to promote the growth of inclusive finance of rural development by using Internet technologies.
\end{abstract}

Keywords: Internet Finance, Inclusive Finance of Rural Development, Financial Innovation, Rural Finance

\section{基于互联网金融的农村普惠金融发展问题研究}

\section{王勍}

经济管理学院, 北京邮电大学, 北京, 中国

\section{邮箱}

wangqingbupt@163.com

摘要：2006年6月中国土地改革新规出台：部分农村土地使用权可抵押贷款，这一措施有利于农村普惠金融的发展; 中国互联网金融自2013年兴起，如今开始向农村方向不断渗透。互联网金融凭借其低成本、便捷性操作，能有力推动 农村普惠金融的发展。论文首先分析了中国农村金融的发展现状、发展中面临的难点，然后从三方面分析互联网金融 对农村普惠金融作用的实现，并提出利用互联网技术促进农村普惠金融发展的建议。

关键词：互联网金融，农村普惠金融，金融创新，农村金融

\section{1. 引言}

自2004年以来，中国政府发布的文件多次聚焦 “三农 问题”, 着力促进农村的全面发展。为促进农村经济发展, 提高农民收入，中国政府一直以来高度重视农村金融发展， 多次出台相关文件强调发展农村金融普惠，十八届三中全
会明确提出发展普惠金融，并将发展农村普惠金融提升到 重要位置。2016年1月份, 《推进普惠金融发展规划 （2016-2020）》的出台实施, 这也体现了中国政府对于 加快金融体系改革和构建新型农村金融体系的重视。

目前中国农村地区金融基础设施落后、金融信用体系 不健全等问题制约了农村经济的发展。互联网金融是以现 代信息科技为基础形成的一种与金融业务相结合的一种 
新的金融融资模式，包括第三方支付、众筹、P2P网贷、 网络金融门户等多种模式。互联网金融尽管在中国起步较 晚, 但是, 它开辟了网络金融的新局面, 为群众提供更加 便捷的支付渠道。互联网金融与农村金融的融合能够破解 农村金融难题，实现金融创新，为农村普惠金融发展提供 新思路和新途径, 同时促进农村进行现代化改革, 让改革 成果惠及于民。

\section{2. 相关文献综述}

农村问题是中国政府一直以来关注的焦点，中国国内 已经有许多学者研究, 互联网金融这一新兴发展模式对于 农村普惠金融的作用以及农村普惠金融在发展中遇到的 难点。农村普惠金融是实现普惠金融的关键，互联网金融 为实现农村普惠金融提供了新思路和解决方案 (李敏, 2015）[1]。目前，中国仍存在许多制约农村普惠金融的 市场障碍和体制机制，农村金融服务基础条件薄弱，金融 市场信息不对称以及农村信用体系处于起步阶段（祝国平, 程呈, 刘军君, 2015）[2]。针对中国农村互联网金融存 在的问题, 利用互联网金融低成本、大数据分析技术以及 互联网金融产品的灵活性、适应性等优势, 推动农村普惠 金融的发展（陈雪瑛，2016）[3]。同时中国政府也要出 台相应的政策，加快农村金融体制机制的改革，推动农村 现代化的发展。发挥传统金融的主体作用，立足于传统金 融的深化发展, 抓住发展互联网金融的机遇, 让二者的良 性互动推动农村普惠金融的发展 (焦姝瑜, 李宏畅, 2015) $[4]$ 。

\section{3. 农村普惠金融发展现状}

\section{1 . 金融排斥的存在}

金融排斥一词从 20 世纪 90 年代开始使用, 金融排斥理 论最初是西方金融地理学家的研究方向之一。农村金融排 斥是指农民群体相对于城市市民更难以接触和使用金融 产品和服务的状态, 农民群体没有足够的能力获得基本的 金融服务, 农村金融排斥涉及金融发展、城乡差距、银行 经营管理和人口素质等多方面问题 (汪星余, 2016) [5]。

据中国社会科学院农村发展研究所社会问题研究中 心调查显示, 中国农村有 $56.8 \%$ 的农户表示资金很紧张, 有 $69.6 \%$ 的农户认为农村贷款不便利。农村金融机构以农 村信用合作社和农村商业银行为主, 主要提供存款业务, 贷款业务相对较少; 受到金融排斥的群体可支配收入有限, 贷款偿还能力较低, 可抵押物和抵押担保不足。农业生产 不同于第二产业和第三产业, 农业受气候等自然条件的影 响大, 2015年, 中国各类自然灾害总共造成农作物受灾面 积21769.8千公顷, 其中绝收 2232.7 千公顷; 直接经济损 失 2704.1 亿元, 中国全国31个省（自治区、直辖市）的近 2500 个县（市、区）不同程度受到自然灾害影响, 受灾县 数约占全国县级行政区总数的 $90 \%[7]$ 。农民由此造成生产 损失, 可能无法还清金融机构的贷款，农民群体在金融机 构的信用度随之下降。同时, 与城市地区相比, 农村地区 经济发展程度低, 农民群体对金融服务的需求低。诸多因
素使得金融排斥一直存在, 不利于农村普惠金融体系的发 展。

\section{2. 农村金融基础设施有待完善}

近年来, 中国农村电商取得较快发展, 促进了农村经 济的发展, 推动了农村部分基础设施的建设。中国农村地 区金融机构以农村信用合作社和农村商业银行为主，但总 体上来看, 平均覆盖率仍然较低, 例如农村商业银行数量 虽然逐年增加（见图表1），但仍无法满足广大农民的需 求，农村金融机构基本的存取款服务已能基本覆盖，但理 财产品服务、保险等仍需进一步加强, 适合农民自身特色 的金融产品服务数量少。在一些偏远农村地区，交通不便 利, 光缆网络或通讯网络尚未布设, 缺乏互联网基础设施, 直接造成互联网金融业务开通受到阻碍。2014年6月至 2016年6月, 中国农村互联网普及率呈现缓慢增长趋势, 截止到2016年6月, 农村互联网普及率只有 $31.7 \%$, 远低于 中国城镇地区, 城乡差距较大 (见图表2)。另一方面, 由于农村居住点较分散, 互联网铺设成本比城镇地区高, 导致互联网使用费用过高, 加上农民收入相对较低, 影响 着一些农民开通使用互联网。此外, 专门的电子商务平台 的缺乏也制约着农村普惠金融的发展。

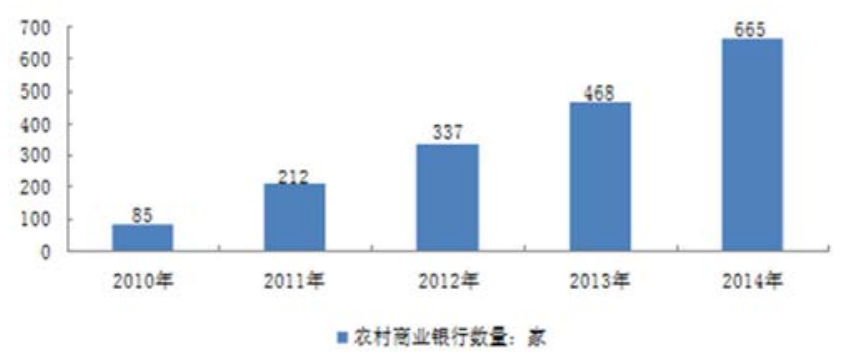

数据来源: 中国产业信息网发布

图1 中国农村商业银行数量（2012年-2014年）。

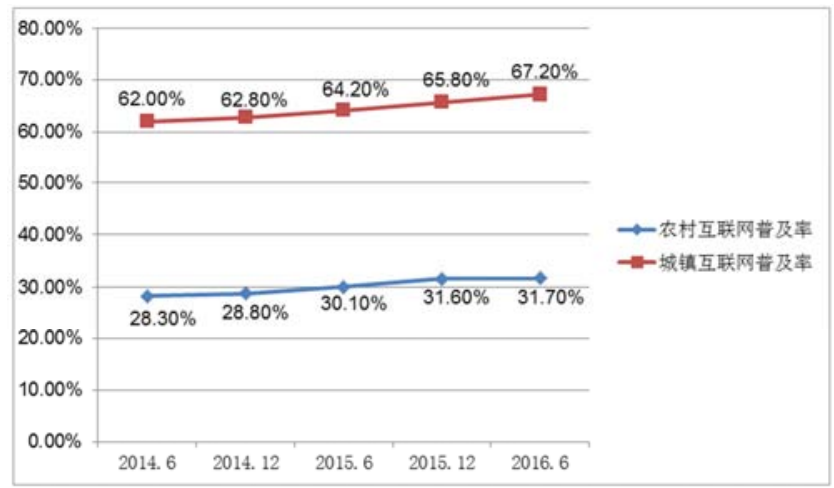

数据来源: 中国互联网络信息中心

图2 中国城乡互联网普及率。

\section{3. 农民金融及互联网知识薄弱, 农村金融服务发展落} 后

在家庭联产承包责任制下, 中国农业主要以个体经营 为主, 目前中国农村 “空心化” 现象严重, 大量地年轻劳 
动力外流, 农村常住居民主要是老人和留守儿童, 其掌握 的互联网和金融知识较少, 文化程度相对较低。

一方面, 由于互联网普及过程中存在的障碍, 一些农 民对网络技术的使用率低, 制约着农民进行互联网消费; 农民习惯于现金结算支付, 网络银行和手机银行的使用程 度较低。根据2016年6月中国互联网络信息中心发布的《第 38次中国互联网络发展状况统计报告》数据显示, 截止到 2016年6月份，中国网民规模达 7.10 亿，中国农村网民占 比 $26.9 \%$, 规模达到 1.91 亿, 较2015年底年减少了 4000 万 人。此外, 中国农村非网民因为不懂网络或电脑而不愿上 网的比例达到68\%, 农民互联网知识薄弱一定程度上限制 了互联网金融下的农村金融体系的发展。

另一方面, 储蓄的传统观念影响较大, 农村金融机构 即使有相关的贷款政策，农民更倾向于放弃消费或者进行 民间借贷; 农民由于收入不稳定, 诚信借贷意识不强, 不 能及时还清银行贷款。此外, 农民对于非法网站的识别能 力弱, 加上一些网络计骗案件的发生和报道, 大大增加了 农民对互联网金融业务的不信任感。

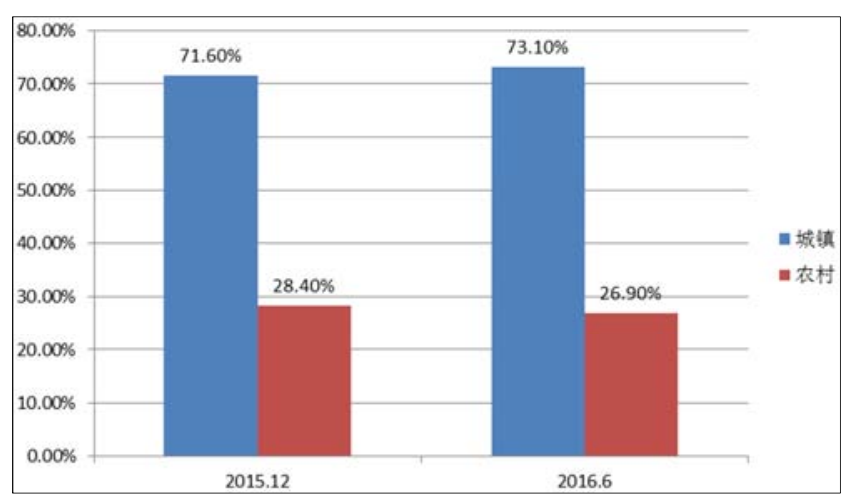

数据来源: 中国互联网络信息中心

图3 中国网民城乡结构。

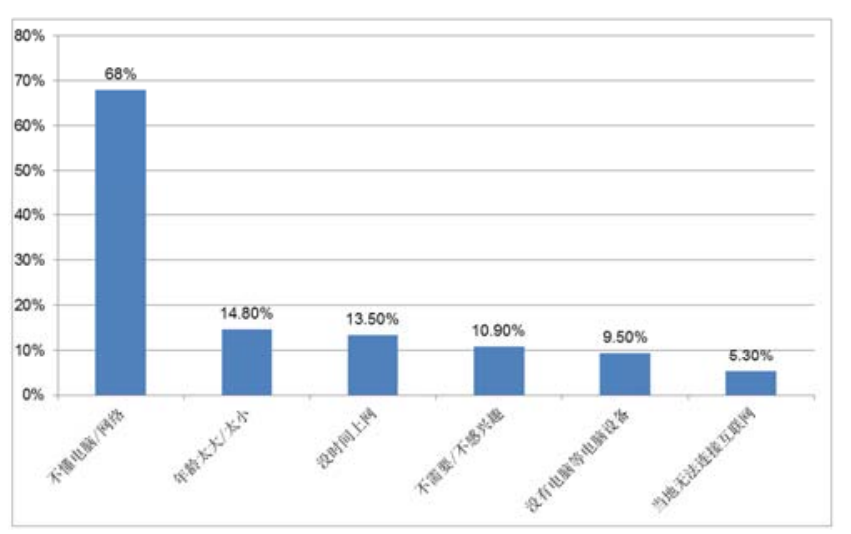

数据来源: 中国互联网络信息中心

图4 农村非网民不上网原因。

\section{4. 农村信用体系不够健全}

农村金融市场上信息不对称问题是较为突出并长期 存在的问题，健全信用体系，改善我国农村金融市场信用 环境是推动农村普惠金融发展的重要因素。农民的生产活 动具有季节性, 收入相对不高, 缺乏金融部门认可的有效
抵押物, 一些抵押物产权不清, 如耕地和农户宅基地, 难 以抵押; 有的存在缺乏市场估值体系、价值波动风险较大 的问题，如农产品、农业机具等生产资料。

中国尚未出台相关的法律法规，对农村金融信用进行 统一管理; 再者, 中国目前缺乏专业的农村金融征信机构, 征信中介机构可能存在虚假信息记录等问题, 其提供的征 信信息参考和信息共享性低, 对基础信用信息缺乏有效的 管理以及缺少信息的核对，考察信息的真实性; 农村信用 合作社等农村金融机构作为农民办理存贷款业务的主要 机构, 没有采集农民信用信息基础数据, 建立农村信用数 据库。作为农村普惠金融服务的需求者, 农民自身的守信 意识不强, 这也制约着农村信用体系的完善。

\section{4. 互联网金融对农村普惠金融发展的作用分析}

\section{1. 利用现代信息技术促进农村普惠金融的融资}

互联网金融借助大数据、云计算等现代信息技术，能 够在一定程度上缓解信息不对称的问题，将企业经营状况、 交易信息透明化, 优化授信业务流程, 提高授信业务效率, 降低授信业务成本, 及时查询和掌握企业运营状况, 在一 定程度上解决乡村企业融资困难的问题, 更大程度地满足 农民和企业的融资需求，降低融资成本; 互联网金融包括 P2P网贷、众筹等多种模式, 有着低成本、低门监、信息 透明等特点, 突破地域和时间限制, 吸收社会闲散资金, 解决农村中小企业资金不足的问题。

2015年9月京东金融以京东电子商务为基础，发布京 东农村金融战略, 即 “ $3 \mathrm{~F}$ ” 战略, 工业品进农村战略 (Factory to Country), 生鲜电商战略 (Farm to Table) 和农村金融战略 (Finance to Country); 京东金融负责人 洪洁表示, 截至2016年9月, 京东已经在全国1500个县、 30 万个行政村开展了各类农村金融业务, 推动了农村经济 的发展。“京农贷” 依托其渠道优势, 利用农产品信贷服 务将贷款发给农户，同时结合农产品众筹方式，由农户或 收购企业在电商平台上销售农产品, 帮助农户和企业完成 贷款融资, 在一定程度上有利于实现农产品和消费者的直 接交易, 降低中间交易成本。

\section{2. 互联网金融发展促进网络技术在农村的普及}

便利的互联网应用是互联网金融业务办理的前提条 件, 农村信息化程度不断提高为互联网金融发展提供了技 术基础。近年来, 中国农村电子商务的快速发展带动农村 创业、就业, 为农村经济提供了新的发展空间, 以及促进 农村产业转型发展, 为农村经济发展注入新的活力。2015 年中国农村网购市场规模达 3530 亿元, 预计 2016 年全年将 达6475亿元。农村电子商务的发展带动了农村地区对互联 网的需求。打开广阔的农村市场, 需要互联网金融企业和 政府的共同努力, 推动信息技术在农村地区的应用和普及, 打通农村金融服务 “最后一公里”; 农村地区的企业和农 民为生产和销售需要, 必须积极学习、掌握网络技术, 了 解金融知识。互联网技术的普及能够让农民和农村企业者 及时了解市场和社会动态, 抓住市场机遇, 帮助其进入更 大的市场体系。 
单位: 亿元

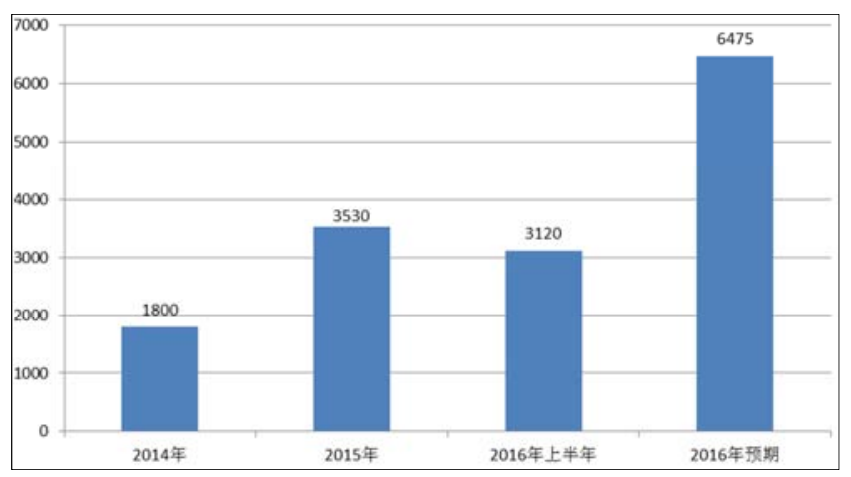

数据来源: 《中国农村电子商务发展报告（2015-2016）》

图5 农村网购交易额。

\section{3. 促进农村信用环境的改善、健全风险分担机制}

互联网金融和农村电子商务的发展需要农户完善必 要信息, 这样有助于取得农户的征信信息和促进互联网大 数据信息体系的完善, 避免因地域因素造成的信息体系不 健全, 提高评估的精确度, 降低主观因素对金融服务的影 响。互联网金融借助大数据技术, 完善信用征信系统, 充 实农户的信用基础数据库; 互联网金融能够缓解农民和农 村企业对于抵押担保不足造成的金融难题, 解决贷款时信 用评估成本高的问题，降低其提供农村金融服务的信息收 集成本，提高金融机构的服务效率和服务水平，推动农村 金融真正实现惠及于民，造福于民。

对于农户来说, 互联网金融在农村地区的发展, 能够 避免出现因无法及时提供抵押物担保, 银行拒绝对其提供 贷款的情况，缓解农户贷款难的局面，健全风险分担机制; 同时也有利于提高农户的信用意识, 及时偿还农村信用社 等金融机构和互联网金融企业的贷款。

\section{5. 互联网金融背景下农村普惠金融发展的建议}

\section{1. 完善互联网金融发展的法律法规, 营造安全的金融 环境}

2013年被称为 “互联网金融元年”，我国互联网金融 发展快, 对我国传统金融的格局的影响不断扩大, 但起步 较晚, 仍缺乏完备的政策制度作为保障。首先, 建立和完 善互联网金融立法, 借鉴其他国家经验, 结合中国的实际 情况, 弥补法律的漏洞, 规范农村互联网普惠金融的发展; 出台相关配套机制, 明确监管主体, 充分发挥第三方和社 会的监督作用，营造稳定安全的金融环境; 各地方政府根 据地区互联网金融和农村普惠金融发展存在的具体问题, 制定符合地方发展需要的指导规范, 对地方涌现出的创新 型农村金融模式和个例进行重点指导。

\section{2. 加强农村基础设施建设}

农村基础设施建设薄弱是制约农村经济发展的重要 因素, 同时互联网金融发展离不开网络基础设施的建设, 因此, 加强农村地区互联网设施建设是发展农村普惠金融
的必由之路。由于互联网基础设施投资成本大、周期长, 政府应当加强财政支持和引导，将政府这只 “看得见的手” 和市场这只 “看不见的手” 结合起来扩大投资规模, 在广 大农村地区布设光缆网络和通讯网络, 提高互联网渗透率 和传输效能, 加强交通建设, 解决 “最后一公里” 难题; 对于偏远、人口分布较少的农村地区, 利用政府财政补贴 和其他优惠措施, 将其聚集在人口密集地区, 降低设施建 设成本和互联网使用费用。建立专门的农村互联网金融和 电子商务平台, 提供农村企业合理的融资渠道, 也为农户 提供投资平台和产品销售平台, 提升产业链的生产效率, 促进农村经济的发展。

\section{3. 加强金融知识的普及力度, 提高农户的金融和网络 水平}

农户作为农村普惠金融的一大主体，其具备的金融水 平和网络应用能力对农村金融的发展有着不可忽视的作 用。可以加强农户的金融和网络教育, 利用手机移动终端 等网络设备了解和学习金融知识; 政府和农村金融机构进 行金融知识、投资理财的相关讲座和培训, 对农村金融机 构的创新业务和金融产品推广宣传, 在一定程度上改变农 户传统的消费理念和投资方式。由此，提高农户的金融意 识, 提升金融知识水平, 真正发挥农户在农村普惠金融中 的主体作用。

\section{4. 健全农村征信体系}

农村征信体系的不完善阻碍了农村金融机构的发展 和其作用的发挥。利用互联网大数据技术, 建立统一的征 信系统, 将农村中小企业和农户纳入征信体系, 完善用户 的基本信息，提高其守信意识; 同时, 实现线上线下的有 机结合，线上系统完善和线下人员监督用户，线上业务和 线下服务实现充分对接，合理利用线下人员、机构的社会 网络、社会资源优势，推进农村金融普惠; 建立专门性的 农村征信机构, 保证农村企业和农民信息的真实性和完整 性。农村征信体系的建立健全是保障农村普惠金融发展的 重要条件, 也是互联网金融在农村发展的推动力。

\section{6. 结论}

尽管目前农村普惠金融存在基础设施不完善、信用体 系不健全等问题, 但互联网金融对农村金融的发展起了重 要作用, 农村互联网金融是农村金融发展的趋势, 基于互 联网金融背景下的农村普惠金融是推动农村经济发展的 一个重要板块, 能够实现农村传统金融和互联网金融的创 新融合, 带动农村金融体系的创新发展和城镇化进程, 促 进全面建成小康社会和 “中国梦” 的实现。

\section{参考文献}

１1］李敏. 互联网金融视角下农村普惠金融的实现机制、难点及 对策 [J].浙江金融, 2015, 12:14-19。 
[2] 祝国平, 程呈, 刘军君. 互联网金融对我国农村普惠金融发展 的作用 $[J]$. 长春金融高等专科学校学报, 2015, 03:13-18。

[3] 陈雪瑛. 互联网金融对农村普惠金融发展作用的探析 [J]. 现代商业, 2016, 07:113-114。

[4]焦姝瑜, 李宏畅. 互联网金融促进农村普惠金融发展研究 [J]. 农村经济与科技, 2015, 05:127-128+188。

[5] 罗宁欣, 颜铭佳. 互联网金融助推农村普惠金融发展问题探 讨 [J]. 农村金融研究, 2016, 05:73-76。

［6］中华人民共和国国家发展和改革委员会经济运行调节 局. 2015年全国自然灾害基本情况. 2016。

［7］《2016-2022年中国农村商业银行市场现状及发展趋势预 测报告》。
[8] 李斯文. 互联网金融背景下农村金融发展研究 [J]. 对外经 贸, 2016, 03:98-99

[9] 孙璐. 探究互联网金融对我国农村普惠金融发展的作用 [J]. 时代金融, 2016, 09:42-43。

[10] 欧家雄. 互联网金融助力农村普惠金融发展的可行性分析 -一以希望金融为例 [J]. 时代金融, 2016, 24:64+76。

[11] 刘斌. 互联网金融助力农村普惠金融发展 $[\mathrm{J}]$. 金融科技时 代, 2015, 11:88-90。

[12] 张天凤. 基于互联网金融的农村普惠金融创新研究 $[\mathrm{J}]$. 商, 2015, 37:173-174。

[13] 任海泉, 梁继锋, 郭文明, 苏强, 何艳太. 互联网金融视角下 农村普惠金融发展实证研究——以朔州市为例 [J]. 华北金 融, 2015, 12:52-57。 